\title{
Portrait-Based Academic Performance Evaluation of College Students from the Perspective of Big Data
}

\author{
https://doi.org/10.3991/ijet.v16i04.20475 \\ Yusong Cao \\ University, Xuchang, China \\ caoyusong1981@126.com
}

\begin{abstract}
With the advent of the big data era, significant changes have taken place in every aspect of education. To effectively evaluate the academic performance of college students, this paper firstly establishes a scientific evaluation index system for student portrait. Taking the course Object-Oriented Programming as an example, the authors collected various data on the academic performance of college students. The collected data were normalized, and the weight of each evaluation index was determined through analytic hierarchy process (AHP). Next, a fuzzy evaluation model was constructed based on big data, and used to assess each dimension of college students' academic performance. The evaluation reveals the problems of college students in learning and practice, and helps to generate the portrait of each student. The research results promote the realization of personalized education.
\end{abstract}

Keywords-Big data, student portrait, academic evaluation, fuzzy evaluation model

\section{Introduction}

Big data and its diverse applications have changed people's life styles and work methods, also brought new opportunities for the innovation in education [1-15]. The Chinese government has attached great importance to education big data; therefore, a series of policies have been issued to promote the construction of education big data, and give guidance to the management and utilization of education big data.

With the advent of the big data era, significant changes have taken place in every aspect of education. Using data mining, learning analysis, data visualization and other technologies, the behavioral data related to the academic performance of college students could be analyzed and integrated to assess the learning situation of college students; moreover, the data obtained via the mentioned techniques also enable college students to discover their problems in the learning and practice process, and the teachers could make use of these data to give targeted and personalized instructions. In the context of big data, the academic performance evaluation of college students has undergone big changes in aspects of ideas, methods and techniques. The totality of big data can give evaluations of college students as a whole; its real-time and dynamic features can realize whole-process evaluation of the academic development process of 
college students; the authentic source of big data ensures that the evaluation results are scientific and objective; and the foreseeability of big data can improve the use efficiency of the evaluation results. Scholars Hamad et al. [16] discussed the opportunities and challenges brought by big data to the analysis strategies of university libraries in Jordan. Vora and Rajamani [17] used big data to predict students' academic performance. Castaneda et al. [18] discussed deep learning evaluation models across multiple big data domains. Wibisono and Sarwinda [19] used big data to predict the student evaluation model in the data stream algorithm. In a word, the development of big data, especially the development of education big data, can promote the overall reform of the academic performance evaluation of college students.

After reviewing the research works of Cumming and Miller [20], Hedgcock [21], Fabra-Mata and Mygind [22] and Amundsen and D'Amico [23] concerning the academic performance evaluation of college students, we have summarized the reform measures for the said matter as follows: first, reform the evaluation methods, that is, apply multiple evaluation methods to evaluate multiple subjects; here multiple subjects include teachers, students, and peers; and multiple evaluation methods can be exams, classroom observations, and practice activities, etc. Second, enrich the evaluation content, that is, construct scientific evaluation index system to give comprehensive evaluations to students from various aspects such as their morality, intelligence, and physical fitness, etc. Third, increase the utilization of evaluation results, that is, timely feedback the evaluation results to the students so that they could correct their problems in time. Fourth, carry out studies on student academic performance evaluation using big data technologies.

The literature review we conducted suggested that currently there're very few research papers concerning the evaluation of the academic performance of college students using big data, and a few relevant studies were aimed at designing personalized learning evaluation systems borrowing the idea of big data concept; moreover, the data of such systems were mostly collected from the online learning trajectories of students, offline evaluation factors were less considered. In addition, one-sided learning evaluation can only evaluate a narrow aspect of the academic performance of college students, for this reason, this study comprehensively considers both the online learning and offline learning of students and constructs a comprehensive evaluation index system; then, the paper conducts an empirical research on the proposed system and achieves personalized and dynamic evaluation of college students' academic performance.

As mentioned above, now there're very few studies directing at the academic performance of college students, and the existing ones mostly centered on the field of basic education; as for studies that have truly applied big data technologies to the evaluation of college students' academic performance, no case has been reported yet. The Ministry of Education has requested to improve the teaching quality of undergraduate education and target at cultivating all-round talents, in this context, it becomes a development trend in the field of education to reform the evaluation concept and content, and make full use of big data, AI and other new-generation information technologies to construct a comprehensive system for the evaluation of college students' academic performance [24-33]. 


\section{Introduction to the Profiling Technique}

As big data have been accumulated continuously and new techniques are being innovated, Recommendation Engines (EO) have become an important starting point for researchers to process information. The deepening understanding of analysis objects has brought out a new concept: the user portraits. A user portrait is a profile that can better describe the user, it makes the information of the user (namely the analysis object) more vivid and alive, and can be processed by computers more easily; it is also the reason for some big companies to employ the big data theories.

The student portraits are used to identify students, and the profiling technique can draw the portraits by analyzing the students: such as what behaviors and habits they have, and their status in the class, etc., it can also reflect their studies through their behaviors. In short, user information tagging. After the learning situations of students have been analyzed, their portraits could be drawn, and an important work in this process is to tag the students, then through the tags on the students, their academic performance could be analyzed more objectively and comprehensively; and the tags make the information processing even easier.

The purpose of student profiling is to give real-time evaluations to the learning process of students. Once the student portraits are drawn, teachers and administrators can have a more accurate and intuitive understanding of the students, and this could serve as a focus for teachers to evaluate the students. When disagreement arises, the portraits of students can always provide a reasonable balance point. Previous academic performance evaluation usually focuses on exam scores, the evaluation results are one-sided and cannot reflect the real ability or potential of the students, that is to say, the traditional GPA (Grade Point Average) evaluation method cannot measure students' development, and such exam-oriented evaluation method is detached from the actual development requirements of the students, resulting in that students attach undue importance to exam scores, students learn for exams, teachers teach for tests, and ultimately, all of them will give negative response to the evaluations.

\subsection{Student portrait index system}

During portrait profiling, a theme runs through the process is how to truly reflect the status of students using the data, and this means that we need to extract registration data, browsing and collection history, feedback information, as well as some text data of students to better evaluate them. For this purpose, we need to find a method to collect all these fragmentary and scattered data and convert into useful and complete information, and this process is just the design and generation of student portraits. According to the actual requirements of the evaluation of college students' academic performance, this paper designed a student portrait index system, which includes the following 20 indexes: average viewing time of teaching videos (video time), number of uploads and downloads of learning resources (resource upload/download), number of borrows of related library books (book borrow), number of times of classroom attendance (classroom attendance), number of questions answered by the student (questions answered), number of valid comments on learning resources (resource 
comment), daily test grades (daily grades), final exam scores, grades of personal works (personal works), time takes to obtain correct experimental results (experiment time), number of times of punctual homework submissions (homework submission), number of questions proposed by the student to teachers (questions proposed), ability to discover problems independently (problem discover), ability to analyze problems independently (problem analysis), classroom notes, team work, experimental reports, accurate analysis of experimental results (experiment analysis), proper data processing method (data processing method), and detailed data processing process explanation (data processing process). In the following texts, these indexes (referred to by the names in the brackets) are employed to analyze the student portraits.

\section{Construction of College Student Portrait Model Based on Big Data}

Education big data is generated from various activities, including both school activities and life activities. Using student portrait model, their learning status could be described and expressed from multiple aspects. For this purpose, we need to study the personalized expression of student portrait model, analyze and normalize the parameters, and construct a personalized student portrait model. Then, based on the full-sided student data obtained, for the complete teaching scenarios, we need to set learning status and result information from different angles and cycles, realize the data-driven portrait model, profile specific and personalized student portraits, and quantify their characteristics from multiple dimensions such as regularity, effort level, and learning skills, etc., in this way, we could provide an important basis for the schools to give comprehensive, scientific and objective evaluations for students.

Table 1. Quantitative learning data of students

\begin{tabular}{|l|c|c|c|c|}
\hline \multicolumn{1}{|c|}{ Index } & Student 1 & Student 2 & Student 3 & Student 4 \\
\hline Video time & 25.22 & 8.15 & 27.23 & 22.22 \\
\hline Resource upload/download & 10 & 6 & 8 & 9 \\
\hline Book borrow & 1 & 1 & 0 & 3 \\
\hline Classroom attendance & 8 & 8 & 6 & 6 \\
\hline Questions answered & 5 & 6 & 5 & 6 \\
\hline Resource comment & 2 & 3 & 0 & 3 \\
\hline Daily grades & 85 & 60 & 82 & 75 \\
\hline Final exam scores & 75 & 72 & 78 & 72 \\
\hline Personal works & 82 & 81 & 85 & 76 \\
\hline Experiment time & 11.23 & 31 & 12.31 & 25.12 \\
\hline Homework submission & 8 & 7 & 8 & 6 \\
\hline Questions proposed & 12 & 6 & 7 & 6 \\
\hline Index & Student 5 & Student 6 & Student 7 & Student 8 \\
\hline Video time & 23.06 & 25.08 & 29.12 & 28.34 \\
\hline Resource upload/download & 8 & 9 & 8 & 5 \\
\hline Book borrow & 2 & 3 & 2 & 2 \\
\hline Classroom attendance & 8 & 8 & 8 & 5 \\
\hline
\end{tabular}


Paper-Portrait-Based Academic Performance Evaluation of College Students from the Perspective of...

\begin{tabular}{|l|c|c|c|c|}
\hline Questions answered & 2 & 3 & 4 & 3 \\
\hline Resource comment & 1 & 0 & 2 & 2 \\
\hline Daily grades & 65 & 68 & 72 & 75 \\
\hline Final exam scores & 70 & 66 & 65 & 70 \\
\hline Personal works & 70 & 61 & 62 & 62 \\
\hline Experiment time & 20.35 & 27.56 & 15.23 & 22.31 \\
\hline Homework submission & 6 & 5 & 7 & 7 \\
\hline Questions proposed & 8 & 8 & 8 & 7 \\
\hline
\end{tabular}

\subsection{Data collection}

In this study, the course "Object-oriented programming" was taken as the example, 10-times performance data of 8 students in this course were extracted, and some of the learning process data were recorded on the excellent course website. Table 1 shows the quantitative learning data of students in this course. Table 2 shows the qualitative learning data of student 1 for this course.

\subsection{Data processing}

Since the student data came from different aspects, it needs to be normalized. First, based on the automatically generated data on the network platform, the data was divided into five levels: excellent, good, average, poor and very poor. Table 3 shows the evaluation levels of the quantitative data.

Table 2. Qualitative learning data of student 1

\begin{tabular}{|l|c|c|c|c|c|}
\hline \multicolumn{1}{|c|}{ Index } & Excellent & Good & Average & Poor & Very poor \\
\hline Problem discover & 0.8 & 0.2 & 0 & 0 & 0 \\
\hline Problem analysis & 0.5 & 0.3 & 0.2 & 0 & 0 \\
\hline Classroom notes & 0.4 & 0.2 & 0.4 & 0 & 0 \\
\hline Team work & 0.7 & 0.3 & 0 & 0 & 0 \\
\hline Experimental reports & 0.2 & 0.3 & 0.5 & 0 & 0 \\
\hline Experiment analysis & 0.5 & 0.4 & 0.1 & 0 & 0 \\
\hline Data processing method & 0.5 & 0.2 & 0.2 & 0.1 & 0 \\
\hline Data processing process & 0.4 & 0.6 & 0 & 0 & 0 \\
\hline
\end{tabular}

Table 3. Evaluation levels of quantitative data

\begin{tabular}{|l|c|c|c|c|c|}
\hline \multicolumn{1}{|c|}{ Index } & Excellent & Good & Average & Poor & Very poor \\
\hline Video time & $25-30$ & $20-25$ & $15-20$ & $10-15$ & $0-10$ \\
\hline Resource upload/download & $8-10$ & $6-8$ & $4-6$ & $2-4$ & $0-2$ \\
\hline Book borrow & Above 4 times & $3-4$ & 2 & 1 & 0 \\
\hline Classroom attendance & $9-10$ & 8 & $6-7$ & $4-5$ & $0-3$ \\
\hline Questions answered & Above 5 times & $3-4$ & $2-3$ & 1 & 0 \\
\hline Resource comment & Above 5 times & $3-4$ & $2-3$ & 1 & 0 \\
\hline Daily grades & $90-100$ & $80-90$ & $60-75$ & $50-60$ & Below 50 \\
\hline Final exam scores & $90-100$ & $80-90$ & $60-75$ & $50-60$ & Below 50 \\
\hline Personal works & $90-100$ & $80-90$ & $60-75$ & $50-60$ & Below 50 \\
\hline
\end{tabular}




\begin{tabular}{|l|c|c|c|c|c|}
\hline Experiment time & $10-15$ & $16-20$ & $21-25$ & $25-30$ & Above 30 \\
\hline Homework submission & $9-10$ & $7-8$ & $5-6$ & $3-4$ & $0-2$ \\
\hline Questions proposed & Above 10 times & $8-9$ & $6-4$ & $1-3$ & 0 \\
\hline
\end{tabular}

\subsection{Fuzzy evaluation model based on big data}

According to the 20 evaluation indexes and 5 evaluation levels \{excellent, good, average, poor, very poor \} given, a fuzzy relationship evaluation matrix had been constructed in the paper. Based on the big data results on the network platform and the qualitative evaluation data of students, the established fuzzy matrix is as follows:

$$
\boldsymbol{M 1}=\left(\begin{array}{ccccc}
1 & 0 & 0 & 0 & 0 \\
1 & 0 & 0 & 0 & 0 \\
0 & 0 & 0 & 1 & 0 \\
0 & 1 & 0 & 0 & 0 \\
1 & 0 & 0 & 0 & 0 \\
0 & 0 & 1 & 0 & 0 \\
0 & 1 & 0 & 0 & 0 \\
0 & 0 & 1 & 0 & 0 \\
0 & 1 & 0 & 0 & 0 \\
1 & 0 & 0 & 0 & 0 \\
0 & 1 & 0 & 0 & 0 \\
1 & 0 & 0 & 0 & 0 \\
0.8 & 0.2 & 0 & 0 & 0 \\
0.5 & 0.3 & 0.2 & 0 & 0 \\
0.4 & 0.2 & 0.4 & 0 & 0 \\
0.7 & 0.3 & 0 & 0 & 0 \\
0.2 & 0.3 & 0.5 & 0 & 0 \\
0.5 & 0.4 & 0.1 & 0 & 0 \\
0.5 & 0.2 & 0.2 & 0.1 & 0 \\
0.4 & 0.6 & 0 & 0 & 0
\end{array}\right)
$$

Then, the weight values of each evaluation index were determined by AHP, $\mathrm{n}$ experts were invited to give the importance judgment matrix A, each judgment matrix was subject to the consistency test. If it fails to pass the test, it is fed back to the scorer to modify the results. Using eigenvector method, the eigenvector corresponding to the largest eigenvalue of the judgment matrix was obtained, and the obtained eigenvector was the weight values of the indexes. By calculating the largest eigenvalue and conducting the consistency check, the weight vector of the indexes was obtained to be:

$$
\begin{gathered}
\mathrm{A} 1=(0.0378,0.0215,0.0217,0.0637,0.0138,0.0105,0.319, \\
0.0835,0.0651,0.0367,0.0256,0.0187,0.0587,0.0871,0.0322, \\
0.0316,0.0111,0.02,0.0308,0.0109)
\end{gathered}
$$

The weighted fuzzy evaluation matrix is:

$$
A 1 * M 1=\{0.28599,0.55122,0.13801,0.02478,0\}
$$


In order to obtain the comprehensive evaluation results of college students' academic performance, the evaluation levels should be quantified, as shown in Table 4.

Table 4. Coefficients of evaluation levels

\begin{tabular}{|l|c|c|c|c|c|}
\hline \multicolumn{1}{|c|}{ Level } & Excellent & Good & Average & Poor & Very poor \\
\hline Score & $90-100$ & $80-90$ & $70-80$ & $60-70$ & 60 以下 \\
\hline Coefficient & 95 & 85 & 75 & 65 & 50 \\
\hline
\end{tabular}

According to fuzzy evaluation method, the final evaluation result of student 1 in the course "Object-oriented programming" was $95 * 0.28599+85 * 0.55122+75 * 0.13801+65 * 0.02478+50 * 0=86.27019$, the result indicated that the performance of the student in this course was "Good", although his/her exam score was 75 and the evaluation level of the score was average. This shows that students shouldn't be evaluated solely based on one-time exam scores, and the evaluation based on final exam scores cannot objectively reflect the overall learning attitude, learning status, and the learning process and effects of the students. Then, the scores of each index of the student were subject to quantitative analysis, and the specific index scores of student 1 are listed in Table 5 below.

Table 5. Index scores of student 1

\begin{tabular}{|l|c|c|c|}
\hline \multicolumn{1}{|c|}{ Index } & Full score & Actual score & Percentage of score \\
\hline Video time & 3.591 & 3.591 & 1 \\
\hline Resource upload/download & 2.0425 & 2.0425 & 0.684211 \\
\hline Book borrow & 2.0615 & 1.4105 & 0.894737 \\
\hline Classroom attendance & 6.0515 & 5.4145 & 1 \\
\hline Questions answered & 1.311 & 1.311 & 0.789474 \\
\hline Resource comment & 0.9975 & 0.7875 & 0.894737 \\
\hline Daily grades & 30.305 & 27.115 & 0.789474 \\
\hline Final exam scores & 7.9325 & 6.2625 & 0.894737 \\
\hline Personal works & 6.1845 & 5.5335 & 1 \\
\hline Experiment time & 3.4865 & 3.4865 & 0.894737 \\
\hline Homework submission & 2.432 & 2.176 & 0.978947 \\
\hline Questions proposed & 1.7765 & 1.7765 & 0.926316 \\
\hline Problem discover & 5.5765 & 5.4591 & 0.894737 \\
\hline Problem analysis & 8.2745 & 7.6648 & 0.968421 \\
\hline Classroom notes & 3.059 & 2.737 & 0.863158 \\
\hline Team work & 3.002 & 2.9072 & 0.936842 \\
\hline Experimental reports & 1.0545 & 0.9102 & 0.905263 \\
\hline Experiment analysis & 1.9 & 1.78 & 0.936842 \\
\hline Data processing method & 2.926 & 2.6488 & \\
\hline Data processing process & 1.0355 & 0.9701 & \\
\hline
\end{tabular}

According to fuzzy evaluation method, the final fuzzy evaluation matrix of student 2 is: 


$$
\mathrm{A} 2 * \mathrm{M} 2=\{0.136070,0.241980,0.168450,0.3790,0.0745\}
$$

The evaluation result of student 2 in the course "Object-oriented programming" was: $95 * 0.13607+85 * 0.241980+75 * 0.168450+65 * 0.3790+50 * 0.0745=74.4887$. This student's performance in the course was "Average", although the evaluation level of his/her exam score was "Poor". Then, the scores of each index of the student were subject to quantitative analysis, and the specific index scores of student 2 are listed in Table 6 below.

Table 6. Index scores of student 2

\begin{tabular}{|l|c|c|c|}
\hline \multicolumn{1}{|c|}{ Index } & Full score & Actual score & Percentage of score \\
\hline Video time & 3.591 & 1.89 & 0.526316 \\
\hline Resource upload/download & 2.0425 & 1.8275 & 0.894737 \\
\hline Book borrow & 2.0615 & 1.4105 & 0.684211 \\
\hline Classroom attendance & 6.0515 & 5.4145 & 0.894737 \\
\hline Questions answered & 1.311 & 1.311 & 1 \\
\hline Resource comment & 0.9975 & 0.7875 & 0.789474 \\
\hline Daily grades & 30.305 & 20.735 & 0.684211 \\
\hline Final exam scores & 7.9325 & 6.2625 & 0.789474 \\
\hline Personal works & 6.1845 & 5.5335 & 0.894737 \\
\hline Experiment time & 3.4865 & 1.835 & 0.526316 \\
\hline Homework submission & 2.432 & 2.176 & 0.894737 \\
\hline Question proposed & 1.7765 & 1.4025 & 0.789474 \\
\hline Problem discover & 5.5765 & 4.2851 & 0.768421 \\
\hline Problem analysis & 8.2745 & 7.6648 & 0.926316 \\
\hline Classroom notes & 3.059 & 2.737 & 0.894737 \\
\hline Team work & 3.002 & 2.9072 & 0.968421 \\
\hline Experimental reports & 1.0545 & 0.9102 & 0.863158 \\
\hline Experiment analysis & 1.9 & 1.78 & 0.936842 \\
\hline Data processing method & 2.926 & 2.6488 & 0.905263 \\
\hline Data processing process & 1.0355 & 0.9701 & 0.936842 \\
\hline
\end{tabular}


In terms of the percentage of score, the portrait tags of student 2 should be: answer questions actively, analyze experimental results accurately, and good team work ability; however, student 2 needs to work on aspects of the viewing time of teaching videos, and obtaining correct experimental results.

\section{Conclusion}

Based on a constructed student portrait model, this paper established a college student academic performance evaluation model, which laid a good basis for data analysis. Then, through a few selected data analysis methods, a fuzzy evaluation model integrated structured, semi-structured, and unstructured data was proposed, studied, and applied to restore the big data analysis results and express them as specific questions, also, the root of these questions was analysis in the paper. The evaluation suggestions made through data analysis and research could be fed back to the administration departments to assist decision-making. With the established data comparison samples, we can write academic performance reports for individual students and write development evaluation report for the entire student group according to the analysis results, and then give reasonable development suggestions, and build a college student development evaluation mechanism in the context of big data; the analysis results can be used to issue early warnings for the academic progress of college students and predict their academic development level.

\section{Acknowledgement}

This study was sponsored by the research and practice project of higher education teaching reform of Henan province (2019SJGLX023), and the project of young excellent teachers of Henan province (2019GGJS215).

\section{References}

[1] Vidal-Silva, C., Madariaga, E., Jiménez, C., Urzúa, L. (2019). Big data education at the chilean academy: Is this possible? International Journal of Scientific and Technology Research, 8(12): 512-517

[2] Salami, Y.D. (2019). Impacts of sustained public education and improvised source protection on sustainable water resources in the developing world. International Journal of Sustainable Development and Planning, 14(3): 226-236. https://doi.org/10.2495/SDP-V14-N3226-236

[3] Yang, F., Liu, B.X., Zhao, L.Q., Peng, X.F. (2019). Recognition of the purchasing intentions of Wechat users based on forgetting curve. Revue d'Intelligence Artificielle, 33(1): 61-65. https://doi.org/10.18280/ria.330111

[4] Altaye, A.A., Sebastian Nixon, J. (2019). A comparative study on big data applications in higher education, International Journal of Emerging Trends in Engineering Research, 7(12): 739-745. 10.30534/ijeter/2019/027122019 
[5] Deb, K., Banerjee, S., Chatterjee, R.P., Das, A., Bag, R. (2019). Educational website ranking using fuzzy logic and k-means clustering based hybrid method. Ingénierie des Systèmes d'Information, 24(5): 497-506. https://doi.org/10.18280/isi.240506

[6] Liu, W. (2019). Traffic flow prediction based on local mean decomposition and big data analysis. Ingénierie des Systèmes d'Information, 24(5): 547-552. https://doi.org/10. $\underline{18280 / i s i .240513}$

[7] Lassen, A.K., Seth, E.H., Tollnes, T. (2018). Enhancing learning outcomes by introducing BIM in civil engineering studies - experiences from a university college in Norway. International Journal of Sustainable Development and Planning, 13(1): 62-72. https://doi.org/ 10.2495/SDP-V13-N1-62-72

[8] Liu, Q., Zeng, L. (2020). Design and application of experimental teaching system driven by big data technology in economics and management majors, International Journal of Emerging Technologies in Learning, 15(11): 56-66

[9] Shidaganti, G., Prakash, S., Srinivasa, K.G., Kanavalli, A. (2019). An insightful review on educational big data analytics in cloud-based e-learning system, International Journal of Advanced Science and Technology, 28(16): 332-344

[10] Liu, H. (2019). The research of theoretical construction and effect of preschool wisdom education system in the background of big data, Cluster Computing, 22: 13813-13819. https://doi.org/10.1007/s10586-018-2102-6

[11] Madhu, S., Midde, R.R., Ramu, G., Jayanthi, A., Somasekar, J., Ramesh, G., Reddy, P.D.K. (2019). A secured framework to protect association rules in the big data environment using fuzzy logic. Ingénierie des Systèmes d'Information, 24(5): 531-537. https://doi. org/10.18280/isi.240511

[12] Yang, C., Huan, S., Yang, Y. (2020). Application of big data technology in blended teaching of college students: A case study on rain classroom, International Journal of Emerging Technologies in Learning, 15(11): 4-16

[13] Shah, B.D., Choksi, D.B. (2019). Big data analytics model for the education sector, International Journal of Innovative Technology and Exploring Engineering, 8(12): 1785-1789. https://doi.org/10.35940/ijitee.L2834.1081219

[14] Senousy, Y., Hanna, W.K., Shehab, A., Riad, A.M., El-Bakry, H.M., Elkhamisy, N. (2019). Egyptian social insurance big data mining using supervised learning algorithms. Revue d'Intelligence Artificielle, 33(5): 349-357. https://doi.org/10.18280/ria.330504

[15] Cheng, X., Zhao, C.Y. (2019). Prediction of tourist consumption based on Bayesian network and big data. Ingénierie des Systèmes d'Information, 24(5): 491-496. https://doi.org/10.18280/isi.240505

[16] Hamad, F., Fakhuri, H., Abdel Jabbar, S. (2020). Big Data Opportunities and Challenges for Analytics Strategies in Jordanian Academic Libraries. New Review of Academic Librarianship, (just-accepted), 1-19. https://doi.org/10.1080/13614533.2020.1764071

[17] Vora, D.R., Rajamani, K. (2019). A hybrid classification model for prediction of academic performance of students: A big data application. Evolutionary Intelligence, 1-14. https:// doi.org/10.1007/s12065-019-00303-9

[18] Castaneda, G., Morris, P., Khoshgoftaar, T.M. (2019). Evaluation of maxout activations in deep learning across several big data domains. Journal of Big Data, 6(1): 72. https://doi. org/10.1186/s40537-019-0233-0

[19] Wibisono, A., Sarwinda, D. (2019). Average Restrain Divider of Evaluation Value (ARDEV) in data stream algorithm for big data prediction. Knowledge-Based Systems, 176: 29-39. https://doi.org/10.1016/j.knosys.2019.03.019 
[20] Cumming, T., Miller, M.D. (2019). Academic Assessment: Best Practices for Successful Outcomes with Accreditation Evaluation Teams. New Directions for Community Colleges, 186: 81-93.

[21] Hedgcock, J. S. (2012). Academic Evaluation: Review Genres in University Settings. Journal of English for Academic Purposes, 11(2): 166-167. https://doi.org/10.1016/j.jeap. $\underline{2011.07 .001}$

[22] Fabra-Mata, J., Mygind, J. (2019). Big data in evaluation: Experiences from using Twitter analysis to evaluate Norway's contribution to the peace process in Colombia. Evaluation, 25(1): 6-22. https://doi.org/10.1177/1356389018804259

[23] Amundsen, C., D’Amico, L. (2019). Using Theory of Change to evaluate socially-situated, inquiry-based academic professional development. Studies in Educational Evaluation, 61: 196-208. https://doi.org/10.1016/j.stueduc.2019.04.002

[24] Hussein, A., Hussain, M. (2019). Social-media based assessment of academic programs. Studies in Educational Evaluation, 62: 149-157. https://doi.org/10.1016/j.stueduc.2019.06. $\underline{003}$

[25] Gort, M. (2012). Code-switching patterns in the writing-related talk of young emergent bilinguals. Journal of Literacy Research, 44(1): 45-75. https://doi.org/10.1177/1086296X $\underline{11431626}$

[26] Dixon, H., Hawe, E., Hamilton, R. (2020). The case for using exemplars to develop academic self-efficacy. Assessment \& Evaluation in Higher Education, 45(3): 460-471. https://doi.org/10.1080/02602938.2019.1666084

[27] Yung, K.W.H., Cai, Y. (2020). Do secondary school-leaving English examination results predict university students' academic writing performance? A latent profile analysis. Assessment \& Evaluation in Higher Education, 45(4): 629-642. https://doi.org/10.1080/02 $\underline{602938.2019 .1680951}$

[28] Ruan, Q., Wu, Q., Wang, Y., Liu, X., Miao, F. (2019). Effective learning model of user classification based on ensemble learning algorithms. Computing, 101(6): 531-545. https:// doi.org/10.1007/s00607-018-0688-4

[29] Rasmani, K.A., Shen, Q. (2006). Data-driven fuzzy rule generation and its application for student academic performance evaluation. Applied Intelligence, 25(3): 305-319. https:// doi.org/10.1007\%2Fs10489-006-0109-9

[30] Fernandes, E., Holanda, M., Victorino, M., Borges, V., Carvalho, R., Van Erven, G. (2019). Educational data mining: Predictive analysis of academic performance of public school students in the capital of Brazil. Journal of Business Research, 94: 335-343. https:// doi.org/10.1016/j.jbusres.2018.02.012

[31] Regan, P.M., Jesse, J. (2019). Ethical challenges of edtech, big data and personalized learning: twenty-first century student sorting and tracking, Ethics and Information Technology, 21(3): 167-179.

[32] Tulasi, B., Suchithra, R. (2019). Personalized learning environment in higher education through big data and blended learning analytics, International Journal of Recent Technology and Engineering, 8(3): 6236-6239. https://doi.org/10.35940/ijrte.C5778.098319

[33] López-Belmonte, J., Pozo-Sánchez, S., Fuentes-Cabrera, A., Trujillo-Torres, J.-M. (2019). Analytical competences of teachers in big data in the era of digitalized learning, Education Sciences, 9(3): 177. https://doi.org/10.3390/educsci9030177 
Paper-Portrait-Based Academic Performance Evaluation of College Students from the Perspective of...

\section{Author}

Yusong Cao, associate professor, School of Food and Pharmacy, Xuchang Univesity, has been engaged in higher education teaching for a long time. She has presided over six teaching reform projects and published more than fifteen papers on education and teaching reform.

Article submitted 2020-12-12. Resubmitted 2021-01-16. Final acceptance 2021-01-19. Final version published as submitted by the authors. 